\title{
Study on the Design and Teaching Reform of Urban Cognition Practice
}

\author{
Shu-li MA ${ }^{1, *}$, Chao WANG ${ }^{2}$ and Fang LUO ${ }^{1}$ \\ ${ }^{1}$ School of Resources and Environment, University of Jinan, China \\ 2 Jinan Huaiyin District education bureau, Jinan, China \\ ${ }^{*}$ Corresponding author
}

Keywords: Urban cognition practice, Jinan, Humanistic feelings.

\begin{abstract}
It is greatly significant for students to learn humanistic geography courses and cultivate students' humanistic quality. Aiming at the main problems existing in practice teaching in the past, this paper takes jinan as an intern research object, and proposes to optimize the internship route and highlight the subject of internship. To improve the interaction between teachers and students and to cultivate students' humanistic quality and other teaching reform practices. In order to stimulate students' interesting in learning urban history and culture, urban planning, and improve the quality of practice teaching, they can contribute to the cultivation of high-quality humanistic geography and urban planning professionals.
\end{abstract}

\section{城市认识实习线路设计与教学改革研究}

\author{
马姝莉 ${ }^{1, *}$, 王超 ${ }^{2}$, 罗芳1 \\ 1济南大学水利与环境学院, 济南, 中国 \\ 2济南市槐荫区教育局, 济南, 中国
}

关键词: 城市认识实习; 济南; 人文情怀

摘要: 城市认识实习对学生学习人文地理专业课程, 培养学生的人文素养具有十分重要的意 义。针对过去实习教学中存在的主要问题, 文中以济南市为实习研究对象, 提出要优化实习 线路、突出实习主题; 增进师生互动和重视培养学生人文素养等几项教学改革实践对策。以 期激发学生学习城市历史文化、城市规划的兴趣, 提高实习教学质量, 为培养高素质的人文 地理与城乡规划专业人才作贡献。

\section{1. 引言}

对于人文地理与城乡规划专业的授课教师来讲, 以济南市为实习对象的城市认识实习是 一门非常利于培养学生人文情怀并与人文地理与城乡规划专业课紧密结合的实践课程。基于 此, 培养学生乡土情怀的城市认识实习的线路设计与教学研究具有十分重要的意义和实践价 值。

\section{2. 城市认识实习线路设计与教学改革的重要意义}

\section{1 有利于提高实践教学的质量}

城市认识实习是人地专业培养计划中的一个重要实践教学环节, 实习时间是大学二年级 第二个学期。这项实习对于学生进一步巩固课堂教学的理论知识与技术方法, 结合实际提高 学生综合分析问题、解决问题的能力, 为学生进一步学习相关专业课程打下坚实基础, 具有 
十分重要的意义。经过设计优化的以济南市为实习对象的城市认识实习的每一条线路, 都突 出了城市丰富的内涵与魅力, 从而可以转化为学生自己对城市文化与历史的认识与理解。从 而有效地提高实践教学的教学质量。

\section{2 有利于 “城市规划原理 II ”、“城市总体规划” 等专业课课程的学习}

在人地专业的培养计划中, 学生是在学习 “人文地理学”、“城市规划原理 I” 等专业 课程之后, 进行城市认识实习的。之后还要进一步学习人地专业领域以及相关领域的课程, 例如: “城市规划原理 II ”、“城市总体规划” 等等。基于此, 城市认识实习在课程设置中 起着承上启下的重要作用。城市认识实习高度概括和总结了学生在课堂已学习的理论知识, 通过实习学生可以将已学习的理论知识融入实践, 更可以通过教学实践对将要学习的理论知 识进行认知, 为今后课堂学习打下坚实的基础。

\section{3 有利于培养学生关爱城市的人文情怀}

城市认识实习教学重在多听、多看、多想, 注重发现、积极思考。包括了城市的区位、 现状、发展历史、城市与建筑之间的关系, 老街巷对城市文化的影响, 建筑在某一特定环境 中所扮演的角色等。这些丰富的内容可以通过教师的教学引领让学生来发现、来探讨、来感 受。这些内容的实习与教学, 可以在潜移默化中影响学生的价值观, 并培养学生 “关爱城市” 的人文情怀。

\section{3. 济南市作为城市认识实习研究对象的优势分析}

每一座城市都有自己的历史与文化。济南是一座古老的城市, 文化积淀深厚, 是中华文 明的重要发祥地之一。据历史数据显示, 济南汉代筑城, 晋时定邦, 宋朝设府, 清初开埠, 盘点历史, 遗迹尚存 ${ }^{[1]}$ 。

\section{1 济南具有独特的泉水文化}

济南因为具有独特的泉水进而形成了独特的泉水文化。济南市，简称“济”，因境内泉水 众多, 被称为“泉城”, 素有“四面荷花三面柳, 一城山色半城湖”的美誉, 是国家历史文化名城。 济南市仅老城区不足3平方公里的范围内就分布着跑突泉、黑虎泉、珍珠泉、五龙潭等四大泉 群, 100多处泉水。

\section{2 济南老街巷充满浓郁的乡土文化气息}

老济南的每一条街巷都有斑驳的历史和动听的传说，老街巷充满浓郁的乡土文化气息， 具有深厚的文化渊源。比如：跑突泉古称 “泺” ，于是跑突泉南门前的路就成了胨源大街; 舜泉呈 “井” 形，相传上古明君舜曾在此挖井，也称 “舜井”，也就有了享誉济南的舜井街 的称谓。至今很多老街巷仍然较好的保持了原汁原味的老济南风情, 充满着浓郁的乡土气息。

\section{3 济南开埠历史悠久}

济南是中国历史上自开商埠的第一座城市。1904年胶济铁路建成通车后, 清政府把西关 外一块长五里、宽三里的地方划出来作为济南的商埠区, 当时济南纺织业较为兴盛, 按照古 时织物 “长者为经、短者为纬” 的习惯，当局就把商埠区内东西方向的道路命名为 “经”， 南北方向的道路命名为 “纬” , 意在鼓励济南的经贸发展。这在全国独一无二, 是一种很独

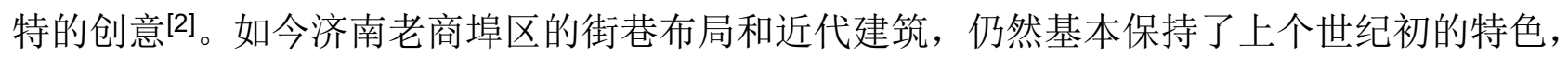
具有丰富的历史文化价值。 


\section{4. 城市认识实习线路设计与教学的现状分析}

\section{1 实习线路设计主题不突出, 内容不充分}

目前城市认识实习授课教师在实习线路设计与教学中, 主要是根据实习目的与要求以济 南市为实习对象进行实习地点的选择与实地考察, 资料收集以及文字叙述。实习内容缺乏结 合城市历史与文化知识的全面扩展, 实习线路设计主题不突出。

\section{2 讲授方式单一, 缺乏师生互动}

在城市认识实习讲授过程中, 实习教师主要采取的是传统的讲授法的方式, 这样的授课 方式使得实习教学成了教师一个人的舞台, 单调且缺乏活力。学生感兴趣的会听讲, 不感兴 趣的或许根本不知所云。这样很难培养学生学习人地专业以及今后相关课程的兴趣, 培养学 生的乡土情怀更是无从谈起。

\section{3 缺乏对学生人文情怀的培养}

很多高校教育工作者认为大学生已经是成年人了, 他们的人生观、世界观、价值观都已 经形成, 无需再重视他们精神世界的教育了。所以在城市认识实习中, 一般缺乏对学生人文 情怀的培养。其实, 这是一种认识上的误区。中国发展心理学界一般把青少年期界定为十一 二岁到十七八岁这段时间 ${ }^{[3]}$ 。大学生正处于从二元思维转向多元思维的关键时期, 他们的人 生观、世界观和价值观仍然具有很强的可塑性。

\section{5. 城市认识实习线路设计与教学改革对策}

\section{1 优化实习线路, 突出主题}

提高城市认识实习的教学质量, 实习线路的设计与优化是其基础和先决条件。笔者以济 南市为实习研究对象, 通过几年的实地考察与调研, 结合人地专业学生课堂理论学习状况, 对城市认识实习线路进行了全面设计与优化, 突出了济南的泉城特色和乡土主题。具体设计 优化了五条实习线路（见表1）：（1）老城古韵: 感受和理解济南的历史发展、文化特色、 老街巷肌理以及古建筑的风采; (2) 泉城明珠: 感受和理解济南古典园林的组成要素、建筑 特色等以及老济南的泉水文化; (3) 近代风貌: 感受、理解济南近代开埠发展历史、文化特 色以及中西合璧式的近代建筑风采; (4) 西部新城: 认识并深入理解现代城市公园的规划布 局特点, 城市公园的功能以及感受西部新城的发展变化; (5) 大学风采: 认识并理解西方哥 特式建筑的特色以及大学校园中轴布局的内涵与特色。

表1 城市认识实习设计线路

\begin{tabular}{|c|c|}
\hline 实习线路主题 & 实习线路内容 \\
\hline 老城古韵 & $\begin{array}{l}\text { 泉城广场——清巡抚旧址（珍珠泉即省人大门口）老街巷（芙蓉 } \\
\text { 街、后宰门街、县西巷、曲水亭街、鞭指巷、将军庙街等）—文庙 }\end{array}$ \\
\hline 泉城明珠 & 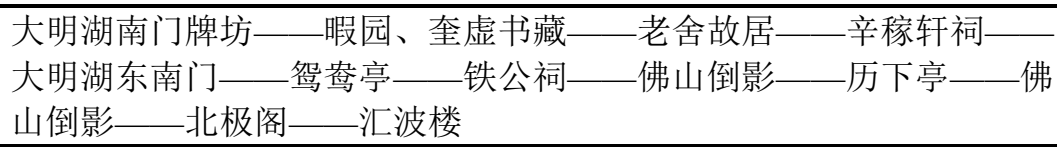 \\
\hline 近代风貌 & $\begin{array}{l}\text { 原胶济铁路济南站博物馆——蔡公时纪念馆即济南开埠纪念馆——经 } \\
\text { 二路：基督教青年会旧址、交通银行济南分行旧址、德华银行旧址、 } \\
\text { 山东邮务局旧址、德国驻济南领事馆旧址、瑞蚗祥绸布店、亨达利、 } \\
\text { 隆祥布店（西记）旧址、宏记堂西号 }\end{array}$ \\
\hline 西部新城 & $\begin{array}{l}\text { 济南高铁西客站一一济南市省会文化艺术中心美术馆、图书馆、群众 } \\
\text { 艺术馆一一济南市西郊森林公园 }\end{array}$ \\
\hline 大学风采 & $\begin{array}{l}\text { 济南洪家楼广场一一洪家楼教堂一一山东大学老校学区一一山东师范 } \\
\text { 大学老校一线。 }\end{array}$ \\
\hline
\end{tabular}




\section{2 加强实习教学活动中的师生交流与互动}

实习教学过程中为了充分发挥教师的主导作用和学生的主体作用, 笔者结合实习教学内 容, 尝试了 “开放式” 教学模式中的一种教学方法即 “激趣一讲解一问题一反馈一矫正” [4]。 具体做法是: 先结合实习内容设计 1 2个可以引起学生兴趣与共鸣的问题, 在讲授过程中, 先通过内容的介绍激发学生的学习兴趣; 再把问题布置给学生, 鼓励学生思考并回答问题; 然后对学生的回答进行矫正和提炼。以讲授济南老商埠区为例, 笔者首先介绍了其发展历史, 然后给学生布置问题思考总结老商埠区建筑的特点以及与老商埠区历史文化的关系。之后带 领学生参观、讲解老商埠区有代表性的建筑, 例如宏济堂药店西记、丰大银行旧址、胶济铁 路济南站等等。参观讲解之后让学生结合所见所闻所想所感畅谈对问题的理解。这个环节极 大地激发了学生的热情, 学生踊跃畅谈自己的理解与收获。最后笔者将这些内容进行评价, 进一步提炼出老商埠区的历史文化与建筑特色。

\section{3 重视培养学生 “关爱城市” 的人文素养}

大学阶段正是学生们重塑自我的关键时期, 教师在教学中应该对丰富学生的精神世界给 予足够的重视。而城市认识实习在培养学生人文素养方面具有无可比拟的优势。所以实习教 学中笔者不仅关注如何传授给学生知识和理论, 更关注培养学生 “关爱城市” 的人文素养, 并且贯穿整个实习阶段。例如在带领学生探访济南明府城老街巷中的将军庙街时, 深入浅出 的从将军庙街现存的宗教建筑到曾经的多种宗教建筑兴盛再到这条街发展历史进行了讲解, 让学生生动直观的感受到城市历史文化遗产保护的重要性, 引起学生的共鸣。然后, 结合实 习任务布置学生自己探访考察某一条老街巷并作实习汇报。通过实地讲解和汇报反馈, 潜移 默化地培养了学生 “关爱城市” 的人文素质。

\section{References}

[1] Dream back to old JiNan, Brings back memories of a city

Information on http://ravel.sina.com.cn/china/2014-03-13/1028252769.shtml

[2] There are stories in the name of jinan: Why is it against the earth

Information on http://www.huaxia.com/zhwh/msdl/dl/2011/11/2671319.html

[3] Wan-xue Qi, Science of higher education. Shandong, 2004

[4] Yun-gang Liu, The reform and practice of college humanistic geography teaching in 21st century-The exploration of Sun Yat-sen university, J.Human Geography. 2(2012)156-160. 